\title{
Genetic Variant of PP2A Subunit Gene Confers an Increased Risk of Primary Liver Cancer in Chinese
}

\author{
Youxin Wang ${ }^{1, *}$ \\ Qiuyue Huang ${ }^{1} *$ \\ Xinglei Huang' \\ Huiliu Zhao ${ }^{2}$ \\ Bin Guan' \\ Kechen $\mathrm{Ban}^{3}$ \\ Xuefeng Zhu' \\ Zhixing Ma' \\ Yanmei Tang' \\ Zhaohui Su' \\ Qingqing Nong' \\ 'Department of Environmental Health, \\ School of Public Health, Guangxi Medical \\ University, Nanning, 53002I, People's \\ Republic of China; ${ }^{2}$ Department of \\ Clinical Laboratory, The Affiliated Tumor \\ Hospital of Guangxi Medical University, \\ Nanning, 53002I, People's Republic of \\ China; ${ }^{3}$ Department of Pathology, The \\ University of Texas M. D. Anderson \\ Cancer Center, Houston, TX, 77030 , \\ USA
}

*These authors contributed equally to this work
Correspondence: Qingqing Nong Department of Environmental Health, School of Public Health, Guangxi Medical University, Nanning, 53002I, People's Republic of China

Tel +86-77I-5358|46

$\mathrm{Fax}+86-77 \mathrm{I}-5350823$

Email nnqq@gxmu.edu.cn
Background: Protein phosphatase 2A (PP2A, a serine/threonine phosphatase) is frequently inactivated in many types of cancer, including primary liver cancer (PLC). Genetic variations in PP2A subunits have been reported to be associated with the risk of many types of cancer but rarely in PLC. This study aims to assess the association between functional polymorphisms of PP2A subunit genes and the risk of PLC in Chinese.

Methods: In a case-control study with a total of 541 PLC patients and 547 controls in Guangxi province of Southern China, we genotyped six putatively functional polymorphisms (rs10421191G $>$ A, rs11453459del $>$ insG, rs $1560092 \mathrm{~T}>\mathrm{G}$, rs $7840855 \mathrm{C}>\mathrm{T}, \mathrm{rs} 1255722 \mathrm{G}>\mathrm{A}$ and rs10151527A $>$ C) of three PP2A subunit genes (PPP2R1A, PPP2R2A and PPP2R5E) using matrixassisted laser desorption/ionization time-of-flight (MALDI-TOF) mass spectrometry platform.

Results: The rs11453459insG variant genotypes (ins/ins+del/ins) of PPP2R1A were found to be significantly associated with an increased risk of PLC compared with the del/del genotype (adjusted $\mathrm{OR}=1.290,95 \% \mathrm{CI}=1.009-1.650$ ), and the number of insert $\mathrm{G}$ allele worked in a dose-dependent manner $\left(P_{\text {trend }}=0.007\right)$. The stratified analysis showed that the effects of rs11453459insG variant genotypes were more evident in the subgroup who drink pond-ditch water (adjusted $\mathrm{OR}=3.051,95 \% \mathrm{CI}=1.264-7.364)$ than those never drink $(P=0.041)$. The carriers of rs11453459 del/ins genotype had a significantly lower level of PPP2R1A mRNA expression in liver cancer tissues than those of the del/del genotype $(P=0.021)$. Furthermore, we used microcystin-LR, a carcinogen presents in the pond-ditch water, to treat human peripheral blood mononuclear cells and found that the cells from carriers of rs11453459insG variant genotypes induced more DNA oxidative damages than those from the del/del genotype carriers $(P<0.001)$.

Conclusion: These findings suggest that the PPP2R1A rs11453459del>insG polymorphism is associated with an increased risk of PLC, especially for persons with a history of drinking pond-ditch water. This insertion/deletion polymorphism may be a susceptible biomarker for PLC in Chinese.

Keywords: PP2A, primary liver cancer, insertion/deletion polymorphism, pond-ditch water

\section{Introduction}

Primary liver cancer (PLC), 80\% of which is hepatocellular carcinoma (HCC), ranks the sixth most common cancer and the third leading cause of cancer-related deaths in the world, accounting for 830,180 deaths in 2020. ${ }^{1,2}$ More than half of the global new PLC cases and deaths occurred in China in 2015. ${ }^{3}$ Particularly, Guangxi province in Southern China has the highest incidence of PLC, and accounts for $30.7 \%$ of PLC deaths in China. ${ }^{4}$ Chronic hepatitis B virus (HBV) infection, aflatoxin B1 exposure, and consumption of microcystins (MCs)-contaminated drinking water have been reported to contribute to the unusually high incidence 
of PLC in Guangxi province. ${ }^{5,6}$ Multiple studies have revealed the contributions of genetic variants to the effects of chronic HBV infection and aflatoxin B1 exposure on PLC risk. ${ }^{7,8}$ However, little is known about the roles of genetic variants in the effects of MCs causing PLC.

It has been reported that the underlying carcinogenic mechanism of MCs was through inhibition of protein phosphatase 2A (PP2A). ${ }^{9,10} \mathrm{PP} 2 \mathrm{~A}$ is a serine/threonine phosphatase that involves the regulation of many cellular processes, including metabolism, cell cycle, DNA replication, growth, and apoptosis. ${ }^{11,12}$ The diminished activity of PP2A contributes to the malignant transformation and tumor development. ${ }^{13}$ As a confirmed tumor suppressor, PP2A participates in AKT, WNT and c-MYC signaling pathways. ${ }^{14}$ The PP2A dimeric core enzyme is composed of a catalytic $\mathrm{C}$ subunit (PPP2CA or PPP2CB) and a scaffold A subunit (PPP2R1A or PPP2R1B). The core enzyme interacts with a variable regulatory $\mathrm{B}$ subunit to form the holoenzyme PP2A. ${ }^{15}$ Previous studies have shown that genetic variants in PP2A subunit genes are associated with risks of several cancers, ${ }^{16-22}$ such as lung cancer, $^{20}$ breast cancer ${ }^{21}$ and soft tissue sarcoma. ${ }^{22}$ The mutation W257G of PPP2R1A enhances cancer cell migration through the SRC-JNK-c-Jun pathway and the mutation of B56 $\gamma$-PP2A partially lost tumor-suppressive function. ${ }^{23,24}$ Lin et al reported that a common insertion/ deletion polymorphism ( -241 ins/delG rs11453459) in the promoter of PPP2R1A affected PPP2R1A transcription by disturbing the binding ability of transcription factor NF$\kappa \mathrm{B} .{ }^{16}$ However, the association between genetic variations in PP2A and the risk of PLC has been rarely substantiated.

In the present study, we performed a case-control study to test the hypothesis that the genetic variants in PP2A subunit genes (PPP2R1A, PPP2R2A and PPP2R5E) may contribute to the susceptibility of PLC in Guangxi province of Southern China.

\section{Materials and Methods Study Subjects}

In this study, a total of 541 pathologically proved PLC patients (49.8 \pm 10.3 years old, 465 males and 76 females) were recruited between 2016 and 2018 in the Affiliated Tumor Hospital of Guangxi Medical University. During the same period, 547 cancer-free individuals (49.1 \pm 9.7 years old, 461 males and 86 females) were enrolled as a control group. Also, 30 PLC tumor tissues were collected from surgical patients at the same time. All patients were confirmed by at least two pathologists. Patients and normal controls affected by other types of cancer were excluded from this study. After signing a written informed consent, all individuals were interviewed according to a structured questionnaire in order to collect personal information, including alcohol use, HBV infection, drinking pond-ditch water, and other factors including family history of cancer. The participants who had smoked less than 100 cigarettes in their lifetime were defined as nonsmokers, otherwise as smokers. ${ }^{25}$ Similarly, the participants who had consumed alcohol at least once a week for more than one year were defined as drinkers of alcohol and the remaining as nondrinkers of alcohol. ${ }^{26} \mathrm{~A}$ pond/ ditch was defined as a water storage place, about $5-6 \mathrm{~m}$ in width, $100 \mathrm{~m}$ in length, and 1-2 $\mathrm{m}$ deep, usually located nearby residential areas. ${ }^{5}$ Those subjects who had used ponds/ditches as the source of drinking water for 20 years or more were defined as drinkers of pond-ditch water. Each participant was asked to donate $5 \mathrm{~mL}$ of blood for examination. This study was approved by the Medical Ethics Committee of Guangxi Medical University (GXMU-20160303-9). All subjects gave their written informed consent, and the study complied with the Declaration of Helsinki.

\section{SNP Selection}

SNPs in the promoter, exon, and 3'-untranslated regions (3'-UTR) were defined to be potentially functional. By searching the dbSNP database (http://www.ncbi.nlm.nih. gov/), we found four potentially functional SNPs in the three subunits of PP2A with the Minor Allele Frequency (MAF) more than $5 \%$ in the Chinese Han population. They were rs $11453459 \mathrm{del}>$ insG in the promoter of PPP2R1A, rs $10421191 \mathrm{G}>A$ in the $3^{\prime}$-UTR of PPP2R1A, rs $7840855 \mathrm{C}>\mathrm{T}$ in the promoter of $\mathrm{PPP} 2 \mathrm{R} 2 \mathrm{~A}$, and rs $1255722 \mathrm{G}>\mathrm{A}$ in the promoter of PPP2R5E. In addition, we also selected two intron SNPs, rs10151527A $>C$ of PPP2R5E and rs1560092T $>$ G of PPP2R1A, since they had been reported to be associated with cancer risk previously. $^{22}$ Taken together, we selected six SNPs of PP2A subunit genes $(10421191 \mathrm{G}>\mathrm{A}, \mathrm{rs} 1560092 \mathrm{~T}>\mathrm{G}$ and rs11453459del $>$ insG of PPP2R1A; rs7840855C $>\mathrm{T}$ of PPP2R2A; rs1255722G $>A$ and $\operatorname{rs} 10151527 \mathrm{~A}>\mathrm{C}$ of PPP2R5E) in this study.

\section{Genotype Analysis}

The Sequenom MassArray platform was utilized for genotyping (Sequenom, San Diego, CA). The design of 
primers for PCR and extension was accomplished with the software MassARRAY Assay Design 3.1 (Sequenom). The reaction system for a multiplex PCR included $1 \mu \mathrm{L}(20 \mathrm{ng} /$ $\mu \mathrm{L}$ ) of DNA sample, $1.850 \mu \mathrm{L}$ of $\mathrm{H}_{2} \mathrm{O}, 0.625 \mu \mathrm{L}$ of PCR buffer, $0.325 \mu \mathrm{L}$ of $\mathrm{MgCl}_{2}(25 \mathrm{mM}), 0.100 \mu \mathrm{L}$ of dNTP $\operatorname{mix}(25 \mathrm{mM})$ and $1.000 \mu \mathrm{L}$ of primer mix (500 nM), 0.100 $\mu \mathrm{L}$ of HotStar Taq ( 5 units $/ \mu \mathrm{L}$ ). PCR reaction conditions were as follows: $5 \mathrm{~min}$ at $94^{\circ} \mathrm{C}, 45$ cycles of DNA amplification $\left(20 \mathrm{~s}\right.$ at $94^{\circ} \mathrm{C}, 30 \mathrm{~s}$ at $56^{\circ} \mathrm{C}$ and $1 \mathrm{~min}$ at $\left.72^{\circ} \mathrm{C}\right), 3$ min at $72^{\circ} \mathrm{C}$ and cooling at $4^{\circ} \mathrm{C}$. The operations of shrimp alkaline phosphatase and iPLEX Gold extension reactions were strictly in compliance with the manufacturer's instructions. During the experiment, the samples were placed on a SpectroCHIP for detection under the Sequenom matrix-assisted laser desorption/ionization time-of-flight (MALDI-TOF) mass spectrometer. Next, we used Mass Array Typer 4.0 to identify the genotypes according to the calculated mass of the products after the extension reaction.

\section{PPP2RIA mRNA Expression Analysis}

We only examined the mRNA levels of PPP2R1A by quantitative real-time polymerase chain reaction (qRTPCR), because there were no significant associations of PLC risk with SNPs of other PP2A subunit genes. Thirty PLC tumor tissues were used to detect the mRNA levels of PPP2R1A. Genotypes of these samples were all confirmed by sequencing. Total RNA was extracted using TriPure Reagent (Roche Applied Science, Vilvoorde, Belgium) and reverse transcribed to complementary DNA using cDNA synthesis kit ThermoScrept ${ }^{\mathrm{TM}}$ RT-PCR System (Invitrogen, California, USA). Relative mRNA expression level of PPP2R1A and an internal reference gene GAPDH were detected on the ABI Prism 7500 sequence detection system (Applied Biosystems, California, USA) according to the $2^{-\Delta \Delta \mathrm{Ct}}$ method. The primers used for PPP2R1A were 5'-AAC TTC GAC AGT ACT TCC GG AA-3' (forward) and 5'-ATG ATC TCA CTC TTG ACG TTG T-3' (reverse); and for GAPDH 5'-CAT GAG AAG TAT GAC AAC AGC CT-3' and 5'-AGT CCT TCC ACG ATA CCA AAG T-3'. We predicted the binding of transcription factor to PPP2R1A promoter region that the SNPs reside in using UCSC (https://genome.ucsc.edu/) and JASPAR (http://jaspar.genereg.net/) databases.

\section{Detection of DNA Oxidative Damage}

To further explore the contents of DNA damage in individuals with different PPP2R1A genotypes, we determined the basal and MC-LR-induced DNA oxidative damage by 8-hydroxy-2'-deoxyguanosine (8-OHdG) analysis. MC-LR exposure sensitivities were evaluated in 50 additional control subjects. Each control subject donated $6 \mathrm{~mL}$ of human peripheral blood and then human peripheral blood mononuclear cells (PBMCs) were obtained by density gradient centrifugation using lymphocyte separation medium (Tianjin Haoyang Biotechnology Co., Ltd., Tianjin, China). PBMCs were cultured at a density of $1 \times 10^{6}$ cells/mL in RPMI 1640 medium supplemented with $20 \%$ fetal calf serum, $2 \mathrm{mM}$ L-glutamine, $100 \mathrm{U} / \mathrm{mL}$ penicillin and $100 \mathrm{ug} / \mathrm{mL}$ streptomycin, and incubated at $37^{\circ} \mathrm{C}, 5 \%$ $\mathrm{CO}_{2}$ for $24 \mathrm{~h}$. Then the PBMCs of each subject were treated with $3 \mu \mathrm{g} / \mathrm{mL}$ MC-LR (treated group) or medium alone (untreated group) for $24 \mathrm{~h}$. The content of $8-\mathrm{OHdG}$ was detected by an ELISA kit (Nanjing Jiancheng Biology Engineering Institute, Jiangsu, China). ${ }^{27}$ The exact $8-\mathrm{OHdG}$ value of each subject was expressed as the 8-OHdG value of MC-LR-treated group minus the $8-\mathrm{OHdG}$ value of untreated group. ${ }^{28}$

\section{Water Sample Collection and Microcystin-LR Analysis}

In August 2017, eighty-nine samples of different kinds of drinking water (29 samples of pond/ditch water, 30 samples of well water, 30 samples of tap water) were collected in Nanning district of Guangxi province. Briefly, $500 \mathrm{~mL}$ of the water samples were directly collected from $0.5 \mathrm{~m}$ below the surface of the water, and sub-packed in plastic tubes. The tubes were subsequently kept frozen at $-20^{\circ} \mathrm{C}$ until analysis. The levels of microcystin-LR (MCLR) in water were determined with direct competitive enzyme-linked immunosorbent assay kits (Beacon Analytical Systems Inc., Maine, USA), by strictly following the kit instructions.

\section{Statistical Analysis}

Chi-square $\left(\chi^{2}\right)$ test was used to analyze the differences of selected parameters (age, gender, ethnicity, smoking status, alcohol drinking, HBV infection, family history of cancer, and drinking pond-ditch water) between cases and controls. The Hardy-Weinberg equilibrium (HWE) was tested by a goodness-of-fit chi-square test to compare the expected genotype frequencies with observed genotype frequencies in controls. Odds ratios (ORs) and 95\% confidence intervals (CI) were calculated to measure the potential association between genotypes and PLC risk. 
An unconditional logistic regression model was applied to analyze crude and adjusted OR and its 95\% CI without and with adjustment for age, gender, ethnicity, smoking status, alcohol drinking. The logistic model was also used for the trend test. Student's $t$-test and one-way analysis of variance (ANOVA) test were used to examine the difference in the levels of microcystin-LR, 8-OHdG or PPP2R1A mRNA expressions between different subgroups. All the tests were analyzed by the SPSS 22.0 software. Furthermore, the statistical power was calculated by using the PASS Software (https://www.ncss.com). The heterogeneity analysis was calculated by Stata 16.0 software. A two-sided $P$ value $<0.05$ was considered statistically significant.

\section{Results}

\section{Distribution of PP2A Subunit Genes Genotypes and Their Associations with Risk of PLC}

In order to determine whether the six candidate SNPs of PP2A genes were associated with PLC, we examined the genotype distribution of these SNPs in both cases and controls. The demographics of PLC cases and controls are shown in Table 1. There were no significant differences in the distributions of gender, age, ethnicity, smoking status and alcohol drinking between cases and controls, respectively $(P>0.05$ for all). However, the proportions of $\mathrm{HBV}$ infection, family history of cancer and drinking pond-ditch water were significantly different between cases and controls $(P<0.001$ for all $)$.

As shown in Table 2, the genotype frequencies of six SNPs among controls are all in agreement with the Hardy-Weinberg equilibrium $(P>0.05$ for all). The chi-square test showed that the genotype distribution of $\mathrm{rs} 11453459 \mathrm{del}>\mathrm{insG}$ was significantly different between the cases and controls $(P=0.011)$. However, for other five SNPs, no significant association with PLC risk was found $(P>0.05$ for all). Under the co-dominant genetic model, the logistic regression analysis showed that the rs11453459 ins/ins genotype conferred a 2.364-fold risk of PLC compared to the common del/del genotype (adjusted OR $=2.364,95 \% \mathrm{CI}=1.302-4.295, P=0.005)$, but the $\mathrm{del} / \mathrm{ins}$ genotype failed (adjusted $\mathrm{OR}=1.184,95 \% \mathrm{CI}=0.916-1.53$, $P=0.196)$. According to the smallest Akaike's information criterion, the effect of rs $11453459 \mathrm{del}>$ insG best fitted the dominant model. The rs11453459insG variants (ins/ins+del/
Table I The Selected Characteristics Between PLC Cases and Controls Used for Association Study

\begin{tabular}{|c|c|c|c|}
\hline Variables & $\begin{array}{l}\text { Cases } \\
(n=54 I) N(\%)\end{array}$ & $\begin{array}{l}\text { Controls } \\
(n=547) \quad N(\%)\end{array}$ & $P^{a}$ \\
\hline \multicolumn{4}{|l|}{ Gender } \\
\hline Male & $465(86.0)$ & 46I (84.3) & 0.438 \\
\hline Female & $76(14.0)$ & $86(15.7)$ & \\
\hline \multicolumn{4}{|l|}{ Age (years) } \\
\hline$<50$ & 240 (44.4) & $247(45.2)$ & 0.793 \\
\hline$\geq 50$ & 301 (55.6) & $300(54.8)$ & \\
\hline \multicolumn{4}{|l|}{ Ethnicity } \\
\hline $\mathrm{Han}$ & $32 \mid$ (59.3) & $330(60.3)$ & 0.738 \\
\hline Zhuang & $220(40.7)$ & 217 (39.7) & \\
\hline \multicolumn{4}{|l|}{ Smoking status } \\
\hline Ever & $217(40.1)$ & $213(38.9)$ & 0.693 \\
\hline Never & 324 (59.9) & 334 (6I.I) & \\
\hline \multicolumn{4}{|l|}{ Alcohol } \\
\hline drinking & & & \\
\hline Ever & $200(37.0)$ & $189(34.6)$ & 0.406 \\
\hline Never & $34 I$ (63.0) & $358(65.4)$ & \\
\hline \multicolumn{4}{|l|}{ HBV infection } \\
\hline HBsAg $(+)$ & $425(78.6)$ & 63 (II.5) & $<0.001$ \\
\hline HBsAg (-) & $116(21.4)$ & $484(88.5)$ & \\
\hline \multicolumn{4}{|l|}{ Family history } \\
\hline of cancer & & & \\
\hline Yes & I53 (28.3) & $37(6.8)$ & $<0.001$ \\
\hline No & 388 (7I.7) & $510(93.2)$ & \\
\hline \multicolumn{4}{|l|}{$\begin{array}{l}\text { Drinking pond- } \\
\text { ditch water }\end{array}$} \\
\hline Ever & $|3|$ (24.2) & $74(13.5)$ & $<0.001$ \\
\hline Never & $410(75.8)$ & $473(86.5)$ & \\
\hline
\end{tabular}

Note: ${ }^{a} p$ values for a two-sided $\chi^{2}$ test.

Abbreviation: PLC, primary liver cancer.

ins) increased the PLC risk by $29 \%$ when compared to the del/ del genotype (adjusted OR $=1.290,95 \% \mathrm{CI}=1.009-1.650$, $P=0.043$ ). Meanwhile, the trend analysis indicated that the detrimental effect of PPP2R1A rs11453459del>insG exhibited a $\mathrm{G}$ allele dose-dependent manner to increase PLC risk $\left(P_{\text {trend }}=0.007\right)$.

\section{Stratification Analysis of Association Between PPP2R IA rs I |453459del>insG Genotypes and PLC Risk}

We performed stratified analysis to evaluate the effects of other factors on associations between PPP2R1A 
Table 2 Frequency Distribution of Genotypes in PP2A SNPs and Results of Logistic Regression Analysis for Their Associations with PLC Risk

\begin{tabular}{|c|c|c|c|c|c|}
\hline SNPs & Cases $(n=54 I) N(\%)$ & Controls $^{a}(n=547) N(\%)$ & $P^{\mathbf{b}}$ & Crude OR $(95 \% \mathrm{Cl})$ & Adjusted OR $(95 \% \mathrm{Cl})^{\mathrm{c}}$ \\
\hline $\begin{array}{l}\text { rs I } 1453459 \text { del>insG } \\
\text { del/del } \\
\text { del/ins } \\
\text { ins/ins } \\
\text { Trend test } P \text { value } \\
\text { del/ins+ins/ins }\end{array}$ & $\begin{array}{l}319(59.0) \\
186(34.4) \\
36(6.6) \\
222(41.0)\end{array}$ & $\begin{array}{l}355(64.9) \\
175(32.0) \\
17(3.1) \\
192(35.1)\end{array}$ & 0.011 & $\begin{array}{l}1.000 \text { (ref.) } \\
1.183 \text { (0.916-I.528) } \\
2.357 \text { (1.298-4.278) } \\
0.008 \\
1.287(1.007-1.644)\end{array}$ & $\begin{array}{l}1.000 \text { (ref.) } \\
1.184 \text { (0.916-I.53I) } \\
2.364(1.302-4.295) \\
0.007 \\
1.290(1.009-1.650)\end{array}$ \\
\hline $\begin{array}{l}\text { rs|042||9|G>A } \\
\text { GG } \\
\text { GA } \\
\text { AA } \\
\text { Trend test } P \text { value } \\
\text { GA+AA }\end{array}$ & $\begin{array}{l}326(60.2) \\
187(34.6) \\
28(5.2) \\
215(39.8)\end{array}$ & $\begin{array}{l}326(59.6) \\
189(34.6) \\
32(5.8) \\
221(40.4)\end{array}$ & 0.885 & $\begin{array}{l}\mathrm{I} .000 \text { (ref.) } \\
0.989 \text { (0.768-I.275) } \\
0.875(0.5 I 5-1.486) \\
0.713 \\
0.973(0.763-1.240)\end{array}$ & $\begin{array}{l}\mathrm{I} .000 \text { (ref.) } \\
0.993 \text { (0.770-I.28I) } \\
0.878(0.516-1.493) \\
0.734 \\
0.976(0.766-1.245)\end{array}$ \\
\hline $\begin{array}{l}\text { rsI560092T>G } \\
\text { TT } \\
\text { TG } \\
\text { GG } \\
\text { Trend test } P \text { value } \\
\text { TG+GG }\end{array}$ & $\begin{array}{l}217(40.1) \\
261(48.2) \\
63(11.7) \\
217(59.9)\end{array}$ & $\begin{array}{l}22 I(40.4) \\
249(45.5) \\
77(14.1) \\
22 I(59.6)\end{array}$ & 0.430 & $\begin{array}{l}1.000 \text { (ref.) } \\
1.068 \text { (0.827-1.378) } \\
0.833(0.569-1.221) \\
0.601 \\
1.012(0.794-1.290)\end{array}$ & $\begin{array}{l}\text { I.000 (ref.) } \\
\text { I.062 (0.822-I.372) } \\
0.835 \text { (0.569-I.224) } \\
0.595 \\
1.008(0.751-1.285)\end{array}$ \\
\hline $\begin{array}{l}\text { rs7840855C >T } \\
\text { CC } \\
\text { CT } \\
\text { TT } \\
\text { Trend test } P \text { value } \\
\text { CT+TT }\end{array}$ & $\begin{array}{l}352(65.1) \\
160(29.6) \\
29(5.4) \\
189(34.9)\end{array}$ & $\begin{array}{l}346(63.3) \\
177(32.3) \\
24(4.4) \\
201(36.7)\end{array}$ & 0.510 & $\begin{array}{l}1.000 \text { (ref.) } \\
0.889(0.685-1.153) \\
1.188(0.678-2.08 I) \\
0.812 \\
0.924(0.72 I-1.184)\end{array}$ & $\begin{array}{l}1.000 \text { (ref.) } \\
0.891 \quad(0.686-1.158) \\
1.191 \quad(0.679-2.090) \\
0.832 \\
0.928(0.723-1.190)\end{array}$ \\
\hline $\begin{array}{l}\text { rs I255722G>A } \\
\text { GG } \\
\text { GA } \\
\text { AA } \\
\text { Trend test } P \text { value } \\
\text { GA+AA }\end{array}$ & $\begin{array}{l}|9|(35.3) \\
26 \mid(48.2) \\
89(16.5) \\
350(64.7)\end{array}$ & $\begin{array}{l}207(37.8) \\
247(45.2) \\
93(17.0) \\
340(62.2)\end{array}$ & 0.582 & $\begin{array}{l}\text { I.000 (ref.) } \\
\text { I. } 145 \text { (0.88I-I.489) } \\
\text { I.037 (0.730-I.473) } \\
0.64 \mid \\
\text { I.II6 (0.876-I.428) }\end{array}$ & $\begin{array}{l}\text { I.000 (ref.) } \\
\text { I.I4I (0.877-I.485) } \\
\text { I.033 (0.727-I.469) } \\
0.659 \\
\text { I.III (0.868-I.424) }\end{array}$ \\
\hline $\begin{array}{l}\text { rsI0I5I527A }>C \\
\text { AA } \\
\text { AC } \\
\text { CC } \\
\text { Trend test } P \text { value } \\
\text { AC }+C C\end{array}$ & $\begin{array}{l}167(30.9) \\
252(46.6) \\
122(22.5) \\
374(69.1)\end{array}$ & $\begin{array}{l}156(28.5) \\
284(51.9) \\
107(19.6) \\
391(71.5)\end{array}$ & 0.198 & $\begin{array}{l}\mathrm{I} .000 \text { (ref.) } \\
0.829 \text { (0.629-I.093) } \\
\mathrm{I} .065(0.759-1.495) \\
0.881 \\
0.894(0.689-1.159)\end{array}$ & $\begin{array}{l}1.000 \text { (ref.) } \\
0.825(0.626-1.089) \\
1.063(0.756-1.493) \\
0.892 \\
0.890(0.686-1.156)\end{array}$ \\
\hline
\end{tabular}

Notes: ${ }^{a}$ The observed genotype frequencies of the six SNPs among the control subjects were all in agreement with the Hardy-Weinberg equilibrium $(P>0.05$ for all); ${ }^{b} \chi^{2}$ test for differences in distribution of genotype frequencies between cases and controls; ${ }^{c}$ Adjusted in an unconditional logistic regression model that included age, gender, ethnicity, smoking status and alcohol drinking.

Abbreviations: SNPs, single nucleotide polymorphisms; PLC, primary liver cancer.

genotypes and PLC risk. Only the result of rs11453459del>insG was presented because the other SNPs had no significant findings. As shown in Table 3, the increased PLC risk caused by rs11453459insG variant genotypes (ins/ins+del/ins) is more pronounced among individuals who have had a history of drinking pond-ditch water (adjusted OR $=3.051,95 \% \mathrm{CI}=$ 1.264-7.364) than those who have not $\left(P_{\text {heterogeneity }}=\right.$ 0.041). In contrast, there were no significant differences in stratum-ORs among gender, age, ethnicity groups, smoking status, alcohol drinking, HBV infection and family history of cancer $(P>0.05$ for all). 
Table 3 Stratification Analysis of the PPP2RIA rs I 1453459del>insG Genotypes by Selected Variables in PLC Cases and Controls

\begin{tabular}{|c|c|c|c|c|c|c|}
\hline \multirow[t]{2}{*}{ Variables } & \multicolumn{2}{|c|}{ Cases $(n=54 I)$} & \multicolumn{2}{|c|}{ Controls $(n=547)$} & \multirow{2}{*}{$\begin{array}{l}\text { Adjusted OR (95\% } \\
\mathrm{Cl})^{\mathrm{a}} \\
\begin{array}{l}\text { del/ins+ins/ins vs del/ } \\
\text { del }\end{array}\end{array}$} & \multirow[t]{2}{*}{$P_{\text {heterogeneity }}{ }^{\mathrm{b}}$} \\
\hline & $\begin{array}{l}\text { del/del } \\
N(\%)\end{array}$ & $\begin{array}{l}\text { del/instins/ins } \\
\text { N (\%) }\end{array}$ & $\begin{array}{l}\text { del/del } \\
\mathbf{N}(\%)\end{array}$ & $\begin{array}{l}\text { del/instins/ins } \\
\text { N (\%) }\end{array}$ & & \\
\hline \multicolumn{7}{|l|}{ Gender } \\
\hline Male & $273(50.5)$ & $192(35.5)$ & $304(55.6)$ & $157(28.7)$ & 1.354 (0.937-1.957) & 0.550 \\
\hline Female & $46(8.5)$ & $30(5.5)$ & $51(9.3)$ & $35(6.4)$ & $1.003(0.403-2.497)$ & \\
\hline \multicolumn{7}{|l|}{ Age (years) } \\
\hline$<50$ & $142(26.3)$ & $98(18.1)$ & $174(31.8)$ & $73(13.3)$ & 1.568 (0.9I5-2.687) & 0.323 \\
\hline$\geq 50$ & 177 (32.7) & $124(22.9)$ & 181 & $119(21.8)$ & I. $100(0.700-1.729)$ & \\
\hline \multicolumn{7}{|l|}{ Ethnicity } \\
\hline Han & 185 & $136(25.1)$ & $211(38.6)$ & $119(21.8)$ & 1.25 I (0.803-I.949) & 0.686 \\
\hline Zhuang & $134(24.8)$ & $86(15.9)$ & $144(26.3)$ & $73(13.3)$ & I.446 (0.840-2.489) & \\
\hline \multicolumn{7}{|l|}{ Smoking status } \\
\hline Ever & $125(23.1)$ & $92(17.0)$ & $138(25.2)$ & $75(13.7)$ & $1.268(0.739-2.176)$ & 0.698 \\
\hline Never & $194(35.9)$ & $130(24.0)$ & 217 (39.7) & $117(21.4)$ & $1.458(0.926-2.293)$ & \\
\hline \multicolumn{7}{|l|}{ Alcohol drinking } \\
\hline Ever & $123(22.8)$ & $77(14.2)$ & $120(21.9)$ & $69(12.6)$ & I.I53 (0.652-2.042) & 0.488 \\
\hline Never & $196(36.2)$ & $145(26.8)$ & $235(43.0)$ & $123(22.5)$ & $1.488(0.959-2.309)$ & \\
\hline \multicolumn{7}{|c|}{$\begin{array}{l}\text { Drinking pond-ditch } \\
\text { water }\end{array}$} \\
\hline Ever & $77(14.2)$ & $54(10.0)$ & $54(9.9)$ & $20(3.7)$ & 3.051 (1.264-7.364) & 0.041 \\
\hline Never & $242(44.7)$ & $168(31.1)$ & $301(55.0)$ & $172(3 \mid .4)$ & $1.125(0.772-1.640)$ & \\
\hline \multicolumn{7}{|l|}{ HBV infection } \\
\hline HBsAg (+) & $251(46.4)$ & $174(32.1)$ & $44(8.0)$ & $19(3.5)$ & $1.552(0.860-2.799)$ & 0.425 \\
\hline HBsAg (-) & $68(12.6)$ & $48(8.9)$ & $311(56.9)$ & $173(31.6)$ & $1.157(0.755-1.773)$ & \\
\hline \multicolumn{7}{|l|}{$\begin{array}{l}\text { Family history of } \\
\text { cancer }\end{array}$} \\
\hline Yes & $82(15.2)$ & $71(13.1)$ & $22(4.0)$ & $15(2.7)$ & $1.330(0.467-3.786)$ & 0.915 \\
\hline No & $237(43.8)$ & I5I (27.9) & $333(60.9)$ & $177(32.4)$ & $1.252(0.870-1.801)$ & \\
\hline
\end{tabular}

Notes: ${ }^{a}$ ORs were adjusted for age, gender, ethnicity, smoking status, alcohol drinking, HBV infection, family history of cancer and drinking pond-ditch water; ${ }^{\mathrm{b}} P_{\text {heterogeneity }}$ values were calculated to compare the difference of ORs within each stratum.

Abbreviation: PLC, primary liver cancer.

\section{Association of the PPP2RIA}

rs I I453459del>insG Genotypes and PPP2RIA Gene Expression Level

Next, the mRNA levels of PPP2R1A were determined in tumor tissues of 30 PLC patients by qRT-PCR. As shown in Figure 1, the mRNA levels of PPP2R1A are much lower in cases with rs $11453459 \mathrm{del} /$ ins genotypes than those with del/del genotype $(P=0.021)$, suggesting that the rs $11453459 \mathrm{del}>$ insG participated in the regulation of PPP2R1A expression.

\section{Effects of the PPP2RIA} rs I I453459del>insG Polymorphism on the MC-LR-Induced DNA Oxidative

\section{Damage in PBMCs}

We then investigated whether PPP2R1A rs11453459del $>$ insG genotypes may affect the responses of PBMCs against MCLR-induced DNA oxidative damage. After genotyping, we collected PBMCs from 50 control subjects and then treated with MC-LR for one day. As shown in Figure 2, the average level of 8 -OHdG in the ins/ins subgroup $(\mathrm{N}=4)$ was 


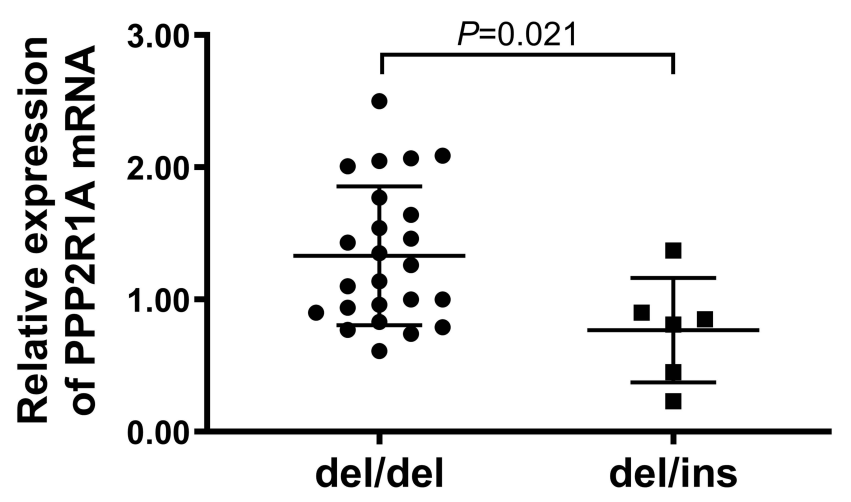

Figure I Relative mRNA expression levels of PPP2RIA in liver cancer tissues with different genotypes of $\mathrm{rs}$ I | 453459 del>insG. The differences in the expression levels were analyzed by Student's $t$-test. The mRNA expression levels of PPP2RIA in 6 cases of liver cancer tissues harboring del/ins genotypes were significantly lower than those in 24 cases harboring del/del genotype.

significantly higher than that of del/ins subgroup $(\mathrm{N}=14, P=$ $0.006)$ and that of del/del subgroup $(\mathrm{N}=32, P<0.001)$. When combined ins/ins and del/ins genotypes, the average level of 8-OHdG in PBMCs of del/del carriers was much lower than that of the other genotypes $(P<0.001)$.

Moreover, we determined the levels of MC-LR in different drinking water types collected in Guangxi province. As shown in Figure 3, the average MC-LR concentration in the pond-ditch water was $0.485 \pm 0.064$ $\mu \mathrm{g} / \mathrm{L}$, much higher than that observed in well water $(0.244 \pm 0.058 \mu \mathrm{g} / \mathrm{L})$ and in tap water $(0.215 \pm 0.018 \mu \mathrm{g} /$ $\mathrm{L})$. Note that the MC-LR levels in all three water types were lower than the limit of $1.0 \mu \mathrm{g} / \mathrm{L}$ in water supply proposed by the World Health Organization. ${ }^{29}$

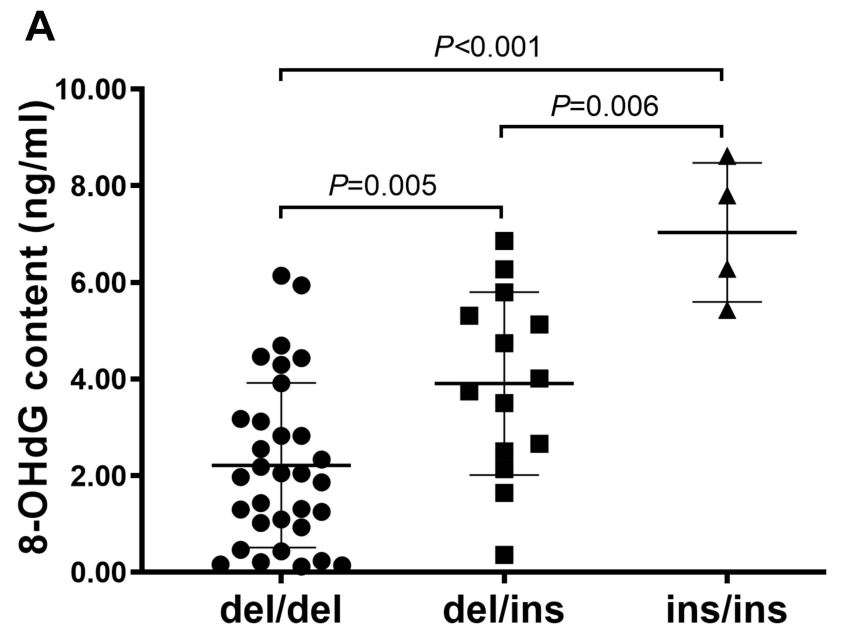

\section{Bioinformatics Analysis}

Because the site of rs11453459 is located in the promoter of PPP2R1A, we further performed bioinformatics analysis to predict whether the rs11453459del $>$ insG polymorphism might affect the binding ability of potent transcription factors (TF) to PPP2R1A promoter. By the use of UCSC and JASPAR databases, we found that the insertion of allele $G$ at the site of -241 in the promoter of PPP2R1A may lose binding site of transcription factor Dp-1 (TFDP1).

\section{Discussion}

In the present case-control study (541 PLC cases and 547 controls) conducted in Guangxi province, we analyzed the associations between six common PP2A SNPs $(10421191 \mathrm{G}>\mathrm{A}, \quad$ rs $1560092 \mathrm{~T}>\mathrm{G}, \quad$ rs11453459del $>$ insG, rs7840855C $>$ T, rs1255722G $>A$ and $r 10151527 \mathrm{~A}>\mathrm{C}$ ) and PLC risk. We found that the PPP2R1A rs11453459insG variant genotypes (ins/ins + del/ins) contributed to an increased PLC risk in a $\mathrm{G}$ allele dose-dependent manner. The increased risk on PLC was more significant in subjects who had a history of drinking pond-ditch water. PLC patients carrying the rs11453459 del/ins genotype showed a lower PPP2R1A expression than those carrying the del/del genotype. In contrast, we did not observe significant associations between any other SNPs in PP2A and PLC risk. To the best of our knowledge, this is the first study to show the association between genetic variants of PP2A and the risk of PLC, especially in individuals with a history of drinking pond-ditch water.

B

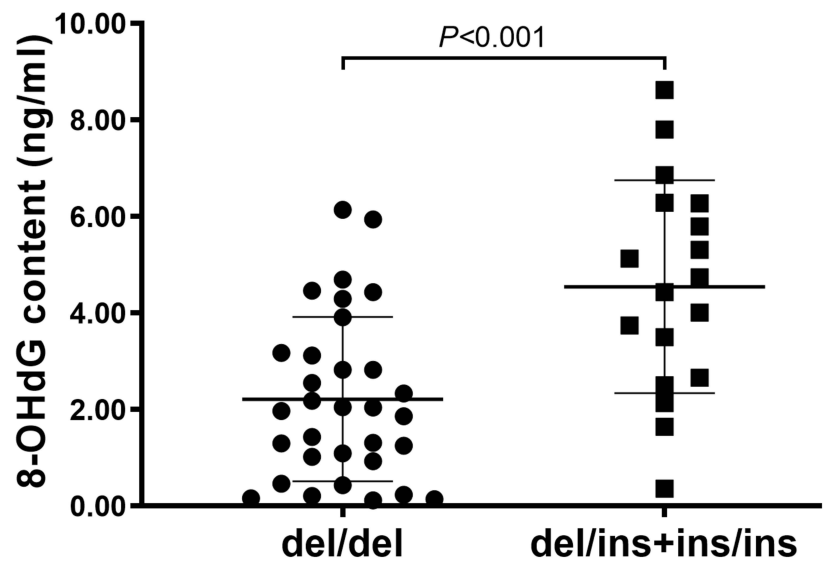

Figure 2 The PPP2RIA rs I 4533459del>insG polymorphism potentiated MC-LR-induced DNA oxidative damage in PBMCs. (A) Comparison of 8-OHdG contents by the three rs I |453459del>insG genotype subgroups. (B) Comparison of 8-OHdG content between the del/del genotype and the other genotypes carriers (del/ins and ins/ins). The levels of 8-OHdG in subjects with different genotypes of rs I l453459del>insG were analyzed with Student's t-test and one-way ANOVA test. 


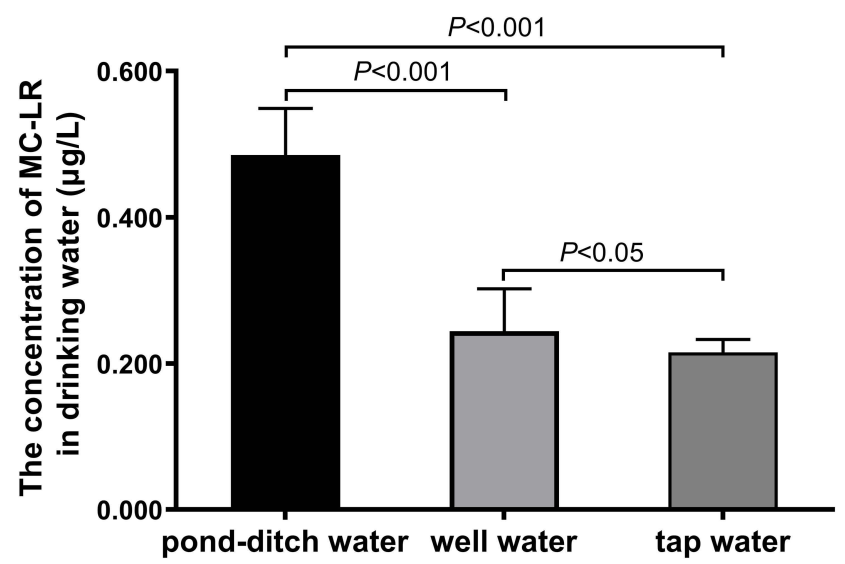

Figure 3 Microcystin-LR levels in different drinking water types collected in Guangxi province. The differences in the microcystin-LR levels were analyzed by one-way ANOVA test.

PPP2R1A serves as a scaffolding molecule to coordinate the assembly of the catalytic subunit and the regulatory B subunit to constitute PP2A. As a negative regulator on controlling cell growth and division, PPP2R1A loss can transform immortalized cells and spur tumorigenicity. ${ }^{21}$ Several studies have reported associations between the polymorphisms of PPP2R1A and cancer risks. Dupont et al found that the SNPs in PPP2R1A were significantly associated with an increased risk of breast cancer in the Nashville population. ${ }^{21}$ Yang et al reported that the rs11453459insG of PPP2R1A contributed to an increased risk of lung cancer in a Chinese population. ${ }^{20}$ Kuhn et al revealed that the SNP in PPP2R1A was associated with uterine serous carcinoma. ${ }^{30}$ These evidences highlighted the application of PPP2R1A SNPs as a possible biomarker for predicting cancer risk.

Among these reported SNPs, the PPP2R1A rs 11453459 del $>$ insG is probably the most investigated. The rs11453459 site is in the promoter of PPP2R1A. It has been reported that the rs $11453459 \mathrm{del}>\mathrm{insG}$ was a functional genetic variant to affect the binding of NF$\kappa \mathrm{B}$ to PPP2R1A promoter and to influence PPP2R1A transcription in human liver cells. ${ }^{19}$ Consistently in the present study, we found that the rs11453459del $>$ insG polymorphism conferred an increased risk of PLC in a Chinese population, possibly through decreased expression of PPP2R1A mRNA in PLC tissues. The bioinformatics analysis further showed that the insertion of allele $G$ at the site of -241 in PPP2R1A may interfere the binding of TFDP1, a transcription factor positively associated with liver cancer. ${ }^{31}$ Therefore, it is biologically conceivable that the genetic variant of PPP2R1A is a possible biomarker for cancer susceptibility.
Particularly, we found that the effects of rs11453459insG variant genotypes on increasing PLC risk were more pronounced in individuals with ever drinking pond-ditch water. Long-term consumption of pondditch water is a potential risk factor for liver cancer, ${ }^{5,32}$ and the high incidence of PLC in Guangxi province may be partially attributed to the high contamination of pondditch water. It had been reported that pond-ditch water was often contaminated by high concentration of blue-green algal toxin microcystin. ${ }^{5,32-34}$ Among the identified over 100 structural analogues of MCs, MC-LR is one of the most abundant and toxic congeners. ${ }^{35}$ MC-LR was classified by the International Agency for Research on Cancer (IARC) as a possible human carcinogen (Group 2B). ${ }^{36} \mathrm{In}$ our present study, much higher levels of MC-LR were observed in pond-ditch water than in tap water.

Interestingly, a previous study revealed that MCs in the pond-ditch water inhibited PP2A activity. ${ }^{37}$ We used MCLR to treat PBMCs and found that the cells from carriers of rs11453459insG variant genotypes were more susceptible to DNA oxidative damage than those from the del/del genotype carriers. The gene-environment interaction between the PPP2R1A rs11453459insG variants and consumption of pond/ditch water on cancer risk is biologically relevant, because the PPP2R1A rs11453459insG variants may decrease PPP2R1A transcription and consequently increase susceptibility to DNA oxidative damage from MC-LR. Further studies are warranted to test the function of the rs11453459insG variants on modulating the protumorigenic effect of MC-LR or pond/ditch water.

There are some limitations in our study. First, the clinical sample size is relatively small. Second, the present study was a hospital-based case-control study, and restricted to Chinese Han and Zhuang population, suggesting the possible presence of selection bias. Third, a considerable proportion of patients lacked clinical information such as tumor staging and differentiation status, which limited our analysis on the association between PPP2R1A variants and clinical features. Nevertheless, the genotype frequencies among controls fitted the HardyWeinberg disequilibrium law. It suggests the randomness of subject selection. Furthermore, the study powers were acceptable. We achieved a $90 \%$ study power (two-sided test, $\alpha=0.05$ ) to detect an OR of 2.364 for the rs 11453459 ins/ins and an OR of 1.290 for the rs11453459insG variant genotypes (ins/ins + del/ins), suggesting that our findings were reliable. 


\section{Conclusions}

In summary, we identified that the PPP2R1A rs11453459del $>$ insG polymorphism was associated with the risk of PLC in a Guangxi population of China. The detrimental effects of the rs11453459insG variants on increasing PLC risk were more pronounced in subjects who had a history of drinking pond-ditch water. Notably, this insertion/deletion polymorphism was functional in PLC as it was associated with the decreased expression of PPP2R1A mRNA. These data suggest that the genetic variant in PPP2R1A (rs11453459del>insG) may act as a potential susceptible biomarker for PLC in Chinese.

\section{Institutional Review Board Statement}

This study was approved by the Medical Ethics Committee of Guangxi Medical University (GXMU-20160303-9). Written informed consent was obtained from all included subjects.

\section{Informed Consent Statement}

Informed consent was obtained from all subjects involved in the study.

\section{Author Contributions}

All authors made substantial contributions to conception and design, acquisition of data, or analysis and interpretation of data; took part in drafting the article or revising it critically for important intellectual content; agreed to submit to the current journal; gave final approval of the version to be published; and agree to be accountable for all aspects of the work.

\section{Funding}

This study was supported by grants from the National Natural Science Foundation of China (No.81660529 and No.81960582).

\section{Disclosure}

The authors declare no conflict of interest.

\section{References}

1. Sung H, Ferlay J, Siegel RL, et al. Global cancer statistics 2020: GLOBOCAN estimates of incidence and mortality worldwide for 36 cancers in 185 countries. CA Cancer J Clin. 2021;71(3):209-249. doi:10.3322/caac. 21660

2. He Y, Lu M, Che J, Chu Q, Zhang P, Chen Y. Biomarkers and future perspectives for hepatocellular carcinoma immunotherapy. Front Oncol. 2021;11:716844. doi:10.3389/fonc.2021.716844
3. Fu J, Wang $\mathrm{H}$. Precision diagnosis and treatment of liver cancer in China. Cancer Lett. 2018;412:283-288. doi:10.1016/j. canlet.2017.10.008

4. Zhang CY, Huang TR, Yu JH, et al. Epidemiological analysis of primary liver cancer in the early 21st century in Guangxi province of China. Chin J Cancer. 2010;29(5):545-550. doi:10.5732/ cjc. 009.10510

5. Ueno Y, Nagata S, Tsutsumi T, et al. Detection of microcystins, a blue-green algal hepatotoxin, in drinking water sampled in Haimen and Fusui, endemic areas of primary liver cancer in China, by highly sensitive immunoassay. Carcinogenesis. 1996;17(6):1317-1321. doi:10.1093/carcin/17.6.1317

6. Xiang X, Qin HG, You XM, et al. Expression of P62 in hepatocellular carcinoma involving hepatitis B virus infection and aflatoxin B1 exposure. Cancer Med. 2017;6(10):2357-2369. doi:10.1002/ cam4.1176

7. Mai H, Xie H, Hou J, et al. A genetic variant of PPP1CB influences risk of hepatitis B virus-related hepatocellular carcinoma in Han Chinese: a pathway based analysis. $J$ Hepatocell Carcinoma. 2021;8:1055-1064. doi:10.2147/JHC.S321939

8. Long XD, Zhao D, Wang C, et al. Genetic polymorphisms in DNA repair genes XRCC4 and XRCC5 and aflatoxin B1-related hepatocellular carcinoma. Epidemiology. 2013;24(5):671-681. doi:10.1097/ EDE.0b013e31829d2744

9. Xiao C, Mei F, Ren G, et al. Synergistic effect of MC-LR and C-terminal truncated $\mathrm{HBx}$ on HepG2 cells and their effects on PP2A mediated downstream target of MAPK signaling pathway. Front Genet. 2020;11:537785. doi:10.3389/fgene.2020.537785

10. Jia X, Guan B, Liao J, et al. Down-regulation of GCLC is involved in microcystin-LR-induced malignant transformation of human liver cells. Toxicology. 2019;421:49-58. doi:10.1016/j.tox.2019.03.010

11. Lei X, Ma N, Du L, et al. PP2A and tumor radiotherapy. Hereditas. 2020;157(1):36. doi:10.1186/s41065-020-00149-7

12. Sandal P, Jong CJ, Merrill RA, Song J, Strack S. Protein phosphatase $2 \mathrm{~A}$ - structure, function and role in neurodevelopmental disorders. J Cell Sci. 2021;134(13):jcs248187. doi:10.1242/jcs.248187

13. Taylor SE, O'Connor CM, Wang Z, et al. The highly recurrent PP2A $\mathrm{A} \alpha$-subunit mutation $\mathrm{P} 179 \mathrm{R}$ alters protein structure and impairs PP2A enzyme function to promote endometrial tumorigenesis. Cancer Res. 2019;79(16):4242-4257. doi:10.1158/0008-5472.CAN19-0218

14. Sablina AA, Hector M, Colpaert N, Hahn WC. Identification of PP2A complexes and pathways involved in cell transformation. Cancer Res. 2010;70(24):10474-10484. doi:10.1158/0008-5472.CAN-10-2855

15. Fowle H, Zhao Z, Graña X. PP2A holoenzymes, substrate specificity driving cellular functions and deregulation in cancer. Adv Cancer Res. 2019;144:55-93.

16. Lin YC, Chen HF, Lin LN, et al. Identification and functional analyses of polymorphism haplotypes of protein phosphatase $2 \mathrm{~A}-\mathrm{A} \alpha$ gene promoter. Mutat Res. 2011;716(1-2):66-75. doi:10.1016/j. mrfmmm.2011.08.004

17. Huang $\mathrm{T}$, He K, Mao Y, et al. Genetic variants in PPP2CA are associated with gastric cancer risk in a Chinese population. Sci Rep. 2017;7(1):11499. doi:10.1038/s41598-017-12040-z

18. Cheng Y, Liu W, Kim ST, et al. Evaluation of PPP2R2A as a prostate cancer susceptibility gene: a comprehensive germline and somatic study. Cancer Genet. 2011;204(7):375-381. doi:10.1016/j. cancergen.2011.05.002

19. Chen HF, Mai JR, Wan JX, et al. Role of a novel functional variant in the PPP2R1A promoter on the regulation of PP2A-A $\alpha$ and the risk of hepatocellular carcinoma. PLoS One. 2013;8(3):e59574. doi:10.1371/ journal.pone. 0059574

20. Yang R, Yang L, Qiu F, et al. Functional genetic polymorphisms in PP2A subunit genes confer increased risks of lung cancer in southern and eastern Chinese. PLoS One. 2013;8(10):e77285. doi:10.1371/ journal.pone. 0077285 
21. Dupont WD, Breyer JP, Bradley KM, et al. Protein phosphatase 2A subunit gene haplotypes and proliferative breast disease modify breast cancer risk. Cancer. 2010;116(1):8-19. doi:10.1002/cncr.24702

22. Grochola LF, Vazquez A, Bond EE, et al. Recent natural selection identifies a genetic variant in a regulatory subunit of protein phosphatase 2A that associates with altered cancer risk and survival. Clin Cancer Res. 2009;15(19):6301-6308. doi:10.1158/1078-0432.CCR-09-0797

23. Jeong AL, Han S, Lee S, et al. Patient derived mutation W257G of PPP2R1A enhances cancer cell migration through SRC-JNK-c-Jun pathway. Sci Rep. 2016;6(1):27391. doi:10.1038/srep27391

24. Nobumori Y, Shouse GP, Wu Y, Lee KJ, Shen B, Liu X. B56 tumor-associated mutations provide new mechanisms for B56 PP2A tumor suppressor activity. Mol Cancer Res. 2013;11 (9):995-1003. doi:10.1158/1541-7786.MCR-12-0633

25. Stockwell HG, Goldman AL, Lyman GH, et al. Environmental tobacco smoke and lung cancer risk in nonsmoking women. $J$ Natl Cancer Inst. 1992;84(18):1417-1422. doi:10.1093/jnci/84.18.1417

26. Ruidavets JB, Evans A, Montaye M, et al. Patterns of alcohol consumption and ischaemic heart disease in culturally divergent countries: the prospective epidemiological study of myocardial infarction (PRIME). BMJ. 2010;341:c6077. doi:10.1136/bmj.c6077

27. Li X, Zhao Q, Zhou W, Xu L, Wang Y. Effects of chronic exposure to microcystin-LR on hepatocyte mitochondrial DNA replication in mice. Environ Sci Technol. 2015;49(7):4665-4672. doi:10.1021/ es5059132

28. Yang L, Li Y, Cheng $\mathrm{M}$, et al. A functional polymorphism at microRNA-629-binding site in the 3'-untranslated region of NBS1 gene confers an increased risk of lung cancer in Southern and Eastern Chinese population. Carcinogenesis. 2012;33(2):338-347. doi:10.1093/carcin/bgr272
29. Xu C, He D, Zu Y, Hong S, Hao J, Li J. Microcystin-LR heterologous genetically engineered antibody recombinant and its binding activity improvement and application in immunoassay. $J$ Hazard Mater. 2021;406:124596. doi:10.1016/j.jhazmat.2020.124596

30. Kuhn E, Wu RC, Guan B, et al. Identification of molecular pathway aberrations in uterine serous carcinoma by genome-wide analyses. J Natl Cancer Inst. 2012;104(19):1503-1513. doi:10.1093/jnci/djs345

31. Yang $\mathrm{H}$, Huo J, Li X. Identification and validation of a five-gene prognostic signature for hepatocellular carcinoma. World J Surg Oncol. 2021;19(1):90. doi:10.1186/s12957-021-02202-9

32. Chen J, Zhu J, Wang G, Groopman JD, Kensler TW. Qidong: a crucible for studies on liver cancer etiology and prevention. Cancer Biol Med. 2019;16(1):24-37. doi:10.20892/j.issn.2095-3941.2018.0394

33. Yu SZ. Primary prevention of hepatocellular carcinoma. J Gastroenterol Hepatol. 1995;10(6):674-682. doi:10.1111/j.14401746.1995.tb01370.x

34. Duy TN, Lam PK, Shaw GR, Connell DW. Toxicology and risk assessment of freshwater cyanobacterial (blue-green algal) toxins in water. Rev Environ Contam Toxicol. 2000;163:113-185. doi:10.1007/ 978-1-4757-6429-1 3

35. Kordasht HK, Hassanpour S, Baradaran B, et al. Biosensing of microcystins in water samples; recent advances. Biosens Bioelectron. 2020;165:112403. doi:10.1016/j.bios.2020.112403

36. IARC monographs on the evaluation of carcinogenic risks to humans. Ingested nitrate and nitrite, and cyanobacterial peptide toxins. In: IARC Monographs on the Evaluation of Carcinogenic Risks to Humans; 2010.

37. Fontanillo M, Kohn M. Microcystins: synthesis and structure-activity relationship studies toward PP1 and PP2A. Bioorg Med Chem. 2018;26(6):1118-1126. doi:10.1016/j.bmc.2017.08.040
Pharmacogenomics and Personalized Medicine

\section{Publish your work in this journal}

Pharmacogenomics and Personalized Medicine is an international, peer-reviewed, open access journal characterizing the influence of genotype on pharmacology leading to the development of personalized treatment programs and individualized drug selection for improved safety, efficacy and sustainability. This journal is indexed

\section{Dovepress}

on the American Chemical Society's Chemical Abstracts Service (CAS). The manuscript management system is completely online and includes a very quick and fair peer-review system, which is all easy to use. Visit http://www.dovepress.com/testimonials.php to read real quotes from published authors. 